\title{
Two-pore-domain potassium channels: regulators of many cellular functions
}

\author{
Thomas Budde • Jürgen Daut • Armin Kurtz • \\ Hans-Christian Pape
}

Received: 2 March 2015 / Accepted: 3 March 2015 / Published online: 14 March 2015

(C) Springer-Verlag Berlin Heidelberg 2015

The structure and the gating mechanisms of two-pore-domain potassium channels $\left(\mathrm{K}_{2 \mathrm{P}}\right.$ channels) are becoming clearer [1-3], and we are now beginning to understand physiological functions of the $15 \mathrm{~K}_{2 \mathrm{P}}$ channels present in the human genome. Originally, $\mathrm{K}_{2 \mathrm{P}}$ channels have been regarded as passive leak channels that contribute to setting the resting potential, but in recent years, it has become clear that they can do much more than that. $\mathrm{K}_{2 \mathrm{P}}$ channels are regulated in a very complex way, perhaps in a more complex way than most other potassium channels. They are sensitive to lipids, mechanical stretch, intra- and extracellular $\mathrm{pH}$, temperature, gases such as carbon monoxide and nitric oxide, and other physicochemical stimuli. Acute activation or inhibition of $\mathrm{K}_{2 \mathrm{P}}$ channels plays a major role in the regulation of many cellular functions. In addition, the abundance of $\mathrm{K}_{2 \mathrm{P}}$ channels at the cell surface can be regulated via G-protein-coupled receptors.

Five of the $\mathrm{K}_{2 \mathrm{P}}$ channels (TWIK-1, TWIK-2, THIK-2, TASK-5, KCNK7) have long been regarded as 'silent' channels because they could not be functionally expressed in heterologous expression systems and because no current attributable to these channels could be detected in native cells. However, two of these channels (TWIK-1 and THIK-2) have

T. Budde $\cdot$ H.-C. Pape

Institute of Physiology I, University of Münster,

48149 Münster, Germany

J. Daut $(\bowtie)$

Institute of Physiology and Pathophysiology, University of Marburg,

35037 Marburg, Germany

e-mail: jdaut@staff.uni-marburg.de

A. Kurtz

Institute of Physiology, University of Regensburg,

93053 Regensburg, Germany recently been characterised. It was found that their traffic to and from the surface membrane was regulated by constitutive endocytosis (TWIK-1) or by an intracellular retention signal (THIK-2). It is likely that they are functionally expressed under certain conditions, but their physiological function is still unclear. We expect that the role of the other 'silent' channels will be characterised in the near future.

In the nervous system, $\mathrm{K}_{2 \mathrm{P}}$ channels are critically involved in adjusting the resting membrane potential and shaping the firing properties of neurons. Based on this basal function and their multiple modulations, $\mathrm{K}_{2 \mathrm{P}}$ channels represent important control elements for neuronal output. In thalamocortical relay neurons, TASK-1, TASK-3, and TREK-1 channels are stimulated or inhibited by a number of physicochemical stimuli including neurotransmitters of the ascending arousal system of the brainstem, thereby setting the activity modes of these neurons during wakefulness and sleep.

Enhancement of potassium currents of the $\mathrm{K}_{2 \mathrm{P}}$ family is a plausible mechanism for producing general anaesthesia, a condition with shows some similarities to natural deep sleep. TASK-1, TASK-3, and TREK-1 channels are opened by certain inhalational anaesthetics and are plausible candidates for mediating some of the central anaesthetic effects. TREK-1, TREK-2, and TRESK channels may be involved in the sensation of pain, and their upregulation may represent a possible strategy for the treatment of pain. TRESK channels are abundantly expressed in sensory neurons of the dorsal root ganglion; their unique properties, regulation, and pharmacology may be useful for developing selective activators of these channels. TASK channels are also involved in central and peripheral chemoreception and in the regulation of breathing, and some of these effects may be mediated by their sensitivity to extracellular $\mathrm{pH}$. 
The pathophysiological roles of ion channels in the central nervous system are difficult to study because most of the channels are differentially distributed in various regions of the brain. Yet, researchers have made remarkable progress in understanding the roles of $\mathrm{K}_{2 \mathrm{P}}$ channels in neuroinflammatory diseases and in neuroprotection during cerebral ischemia. Finally, the roles of $\mathrm{K}_{2 \mathrm{P}}$ channels in the electrical activity of the heart, in oxygen sensing in the carotid body, and in hormone release by the adrenal gland have been characterised.

A research consortium (FOR1086) supported by the Deutsche Forschungsgemeinschaft (DFG, German Research Council) set out in 2008 to elucidate the physiology and pathophysiology of $\mathrm{K}_{2 \mathrm{P}}$ channels. The consortium consisting of nine groups based in Germany (Göttingen, Kiel, Marburg, Münster, and Regensburg) has cooperated with an international network of $\mathrm{K}_{2 \mathrm{P}}$ researchers. The members of this network have been invited to summarise the current knowledge on the function of $\mathrm{K}_{2 \mathrm{P}}$ channels. The collection of reviews and original articles compiled in this special issue of Pflügers Archiv, European Journal of Physiology, represents an upto-date overview of the physiology and pathophysiology of $\mathrm{K}_{2 \mathrm{P}}$ channels.

\section{References}

1. Aryal P, Abd-Wahab F, Bucci G, Sansom MS, Tucker SJ (2014) A hydrophobic barrier deep within the inner pore of the TWIK-1 $\mathrm{K}_{2 \mathrm{P}}$ potassium channel. Nat Commun 5:4377

2. Brohawn SG, Campbell EB, MacKinnon R (2013) Domain-swapped chain connectivity and gated membrane access in a Fab-mediated crystal of the human TRAAK $\mathrm{K}^{+}$channel. Proc Natl Acad Sci USA 110:2129-2134

3. Piechotta PL, Rapedius M, Stansfeld PJ, Bollepalli MK, Ehrlich G, Andres-Enguix I, Fritzenschaft H, Decher N, Sansom MS, Tucker SJ, Baukrowitz T (2011) The pore structure and gating mechanism of $\mathrm{K}_{2 \mathrm{P}}$ channels. EMBO J 30:3607-3619 